\title{
MORPHOLOGY AND INTERNAL STRUCTURE OF DIAMONDS FROM THE SNAP LAKE/KING LAKE KIMBERLITE DYKE SYSTEM, SLAVE CRATON, CANADA
}

\author{
Nikolai Pokhilenko ${ }^{1,3}$, Dmitry Zedgenizov ${ }^{1}$, Valentin Afanasiev ${ }^{1}$, Gennagy Rylov ${ }^{1}$, Judith \\ Milledge $^{2}$, Adrian Jones ${ }^{2}$, Anne Hall ${ }^{3}$ and Lada Reimers ${ }^{3}$ \\ ${ }^{1}$ Institute of Mineralogy and Petrography, Novosibirsk, Russia; ${ }^{2}$ University College London, United Kingdom; \\ ${ }^{3}$ Diamondex Resources Ltd., Vancouver, Canada
}

\section{INTRODUCTION}

Snap Lake/King Lake kimberlite dyke system is a new diamond deposit recently discovered in Canada (Slave Craton, NWT). This locality is characterized by anomalous composition of the kimberlites and the unusual lithosphere structure [Pokhilenko et al., 2001a; Agashev et al., 2001]. Mineral inclusions in diamonds from Snap Lake/King Lake are $95 \%$ of peridotitic paragenesis [Pokhilenko et al., 2001b]. Their composition reflects a low degree of depletion of the host peridotites in comparison with that from South Africa and Siberia. The unusual characteristics of the kimberlite create special interest in the diamond formation process. The morphological features along with nucleation, crystallization and post-growth evolution, of the diamonds from Snap Lake/King Lake kimberlites, were studied to reconstruct their growth history

\section{METHODS}

The morphology and internal structure of over 400 crystals have been studied to characterize the growth history of Snap Lake/King Lake diamonds. The crystals were selected from two size ranges: $-4+2 \mathrm{~mm}(2 \mathrm{~mm})$ and $-2+1 \mathrm{~mm}(1 \mathrm{~mm})$. All diamonds were individually examined under a stereomicroscope to distinguish their shape, color and possible inclusions. The main morphological features and surface textures were studied using a scanning electron microscope (SEM) JEOL JSM-35. The Laue-SR method (synchrotron Xradiation source at BINP is the VEPP-3 storage ring in Novosibirsk) was used for the rapid data collection from imperfect diamonds which are hard to investigate with the conventional X-ray methods [Rylov et al., 2001]. Additionally, X-ray topography $\left(\mathrm{MoK}_{\alpha^{-}}\right.$ radiation) was used to study the features of the internal structure of several crystals. Over 50 thin plates were prepared in order to study the of growth history using Cathodoluminescence (CL) at University College, London.

\section{MORPHOLOGY}

\section{Crystal haBit}

Preliminary study of the diamond collection from the Snap Lake kimberlites revealed a wide variety of crystal morphology. Morphological characteristics of the diamonds from both sizes are typical of those from high-grade kimberlites: diamonds of octahedral habit (and macles) predominate (64\% and 56\% respectively for the $2 \mathrm{~mm}$ and $1 \mathrm{~mm}$ sizes). The quantity of macles among octahedra is significant. Rounded crystals (dodecahedroids) are less common (9\% and 5\%). The main characteristic features are, the high content of diamonds of cubic habit (cuboids), and coated diamonds. The proportion of cuboids is higher among the smaller size (up to $16 \%$ for $1 \mathrm{~mm}$ versus $7 \%$ for 2 $\mathrm{mm})$. There are many twins of interpenetrant cuboids. Aggregates (with number of crystals more than 5) are scarce - less than $5 \%$ in both size ranges.

\section{SURFACE TEXTURE}

Most diamonds from Snap Lake/King Lake are either flat-faced octahedra or laminar octahedra with striated appearance (Fig .1a,b). There are often thin colorless coats on the octahedral crystals (Fig. 1c,d). Some of the octahedral diamonds have signs of secondary morphology: rounded edges and trigon etch pits (Fig. 1e). As the degree of resorption increases the octahedra change into rounded crystals with habit similar to rhombic dodecahedra or tetrahexahedra (Fig. 1f). Rounded surfaces have different kinds of relief such as sculptures or striations.

Only a small proportion of cuboids have sharp edges and hummocky or mosaic surface textures, that might be primary growth features (Fig. 1g). Most also have features of resorption - rounded edges, tetragonal etch pits and etch channels (Fig. 1h). 

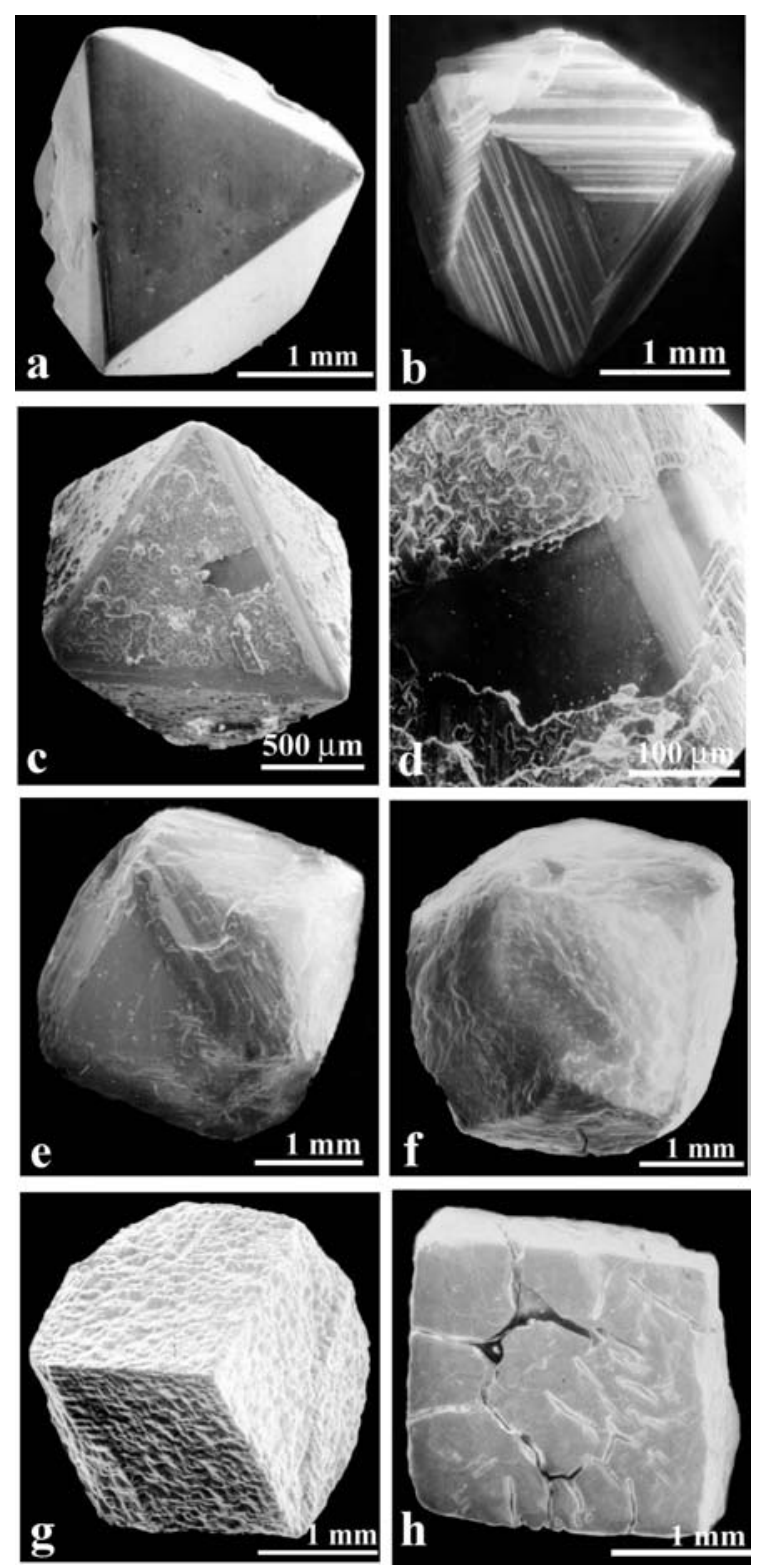

Figure 1: Morphology of diamonds from Snap Lake/King Lake kimberlites. SEM images. Description, in the text.

\section{COLOR}

The diamonds are predominantly colorless (more than $65 \%$ for both sizes). There are many crystals with greenish pigmentation or dark-green spots. Some diamonds have signs of plastic deformation and are brown in color. All cuboids are either translucent gray or yellow or opaque greenish black crystals. The lack of transparency of the cuboids is caused by the presence of numerous sub-micron inclusions making them turbid.

\section{INTERNAL STRUCTURE}

\section{X-RAY METHODS}

The use of Laue-SR is a relatively quick method to study a large number of crystals. There are many perfect crystals of octahedral diamonds among the studied group. Figure 2a shows an X-ray topography image of an octahedron with relatively perfect structure. However, most of the diamonds are distorted octahedra with lesser numbers of dodecahedroids and cuboids. Diffraction reflex-topograms of diamonds with different types and degree of deformation are shown in Figure 2: b) weakly deformed diamond - distortion of shape of diffraction spot; c) deformed diamond asterism with single direction; d) deformed diamond asterism with several directions; e) heavily deformed diamond - lattice rearrangement by means of twining (without change of crystal shape).

Both Laue-SR and X-ray topography of the cuboid diamonds revealed their fibrous internal structure (Fig. $3 a)$. The fibers propagate from the center of the crystals to the periphery and group in cubic growth sectors. The outer zones (coats) of the coated diamonds also have a fibrous structure (Fig. 3b). Along with the fibrous internal structure cuboids have distinct zoning resulting from the alternation of zones saturated with microinclusions and zones that are inclusion-free..
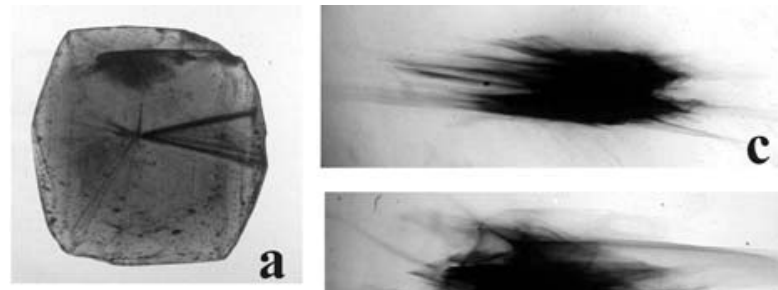

a
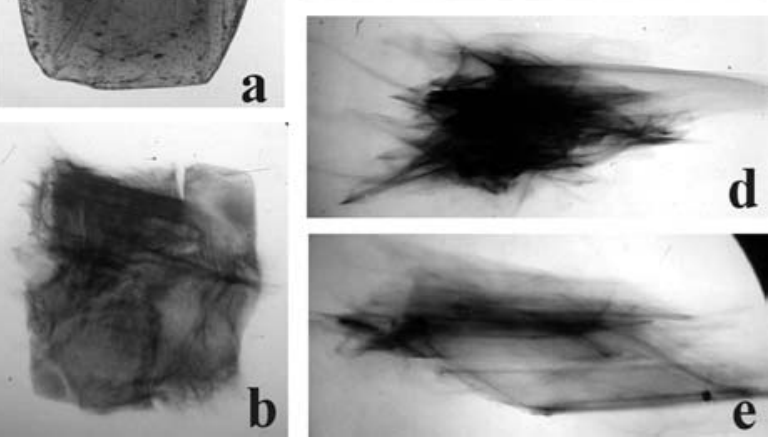

Figure 2: Laue-SR X-ray topograms of diamonds from Snap Lake/King Lake kimberlites. Description, see text.

\section{Cathodoluminescence}

Cathodoluminescence imagery of the octahedradodecahedroid diamonds revealed the predominant linear or stepped octahedral zoning (Fig. $4 \mathrm{a}, \mathrm{b}$ ). The central domains usually have bright blue luminescence 

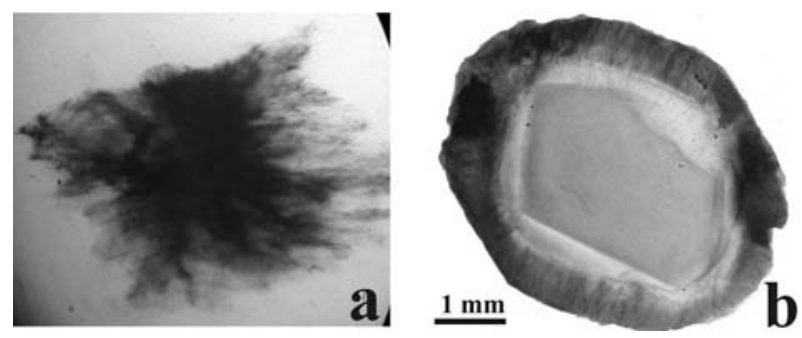

Figure 3: Laue-SR reflex of cuboid (a) and X-ray topograms of coated diamond (b) from Snap Lake/King Lake kimberlites.

and are often represented by a smaller broken or resorbed crystal. Peripheral domains of the octahedra, that reflect the final growth stage, have weaker luminescence. Sometimes the weak yellow luminescence as semicircles due to radiation damage, is observed on the edges of crystals (Fig. 4c). The brown diamonds show the typical presence plastic deformation lines crossing the whole crystal or in specific zones (Fig. 4d). Cuboids and the fibrous coats have very weak cathodoluminescence.

\section{DISCUSSION}

The diversity of morphological features and internal structures resulted from a wide variation of growth conditions and the subsequent post-growth alteration. The paucity of rounded crystals indicates a low overall resorption. Moreover many diamonds have a late stage overgrowth of a fibrous coating. This fact as well as the high content of cuboids is evidence for diamond growth occurring recently before kimberlitic eruption [Boyd et al., 1992]. As Snap Lake/King Lake kimberlites are located in ancient granitoids and the width of the dykes is small, many diamonds have been irradiated by radioactive minerals of the granitoid matrix.

The study of the internal structure shows a complicated growth history for most of the diamonds. There is evidence of several diamond growth stages. Some diamonds have a core represented by a broken or resorbed crystal but re-grew predominantly as octahedra. At a later stage most were deformed probably because of instability of the lithosphere during that period. The last stage of diamond evolution was the growth of fibrous crystals and coats and post-growth resorption. Thus the studied collection of diamonds includes crystals of different generations.

Examination of the distribution and composition of the mineral inclusions reveals that these diamonds were sampled by kimberlite melt from extremely thick lithosphere $(>300 \mathrm{~km})$. This conclusion is supported by

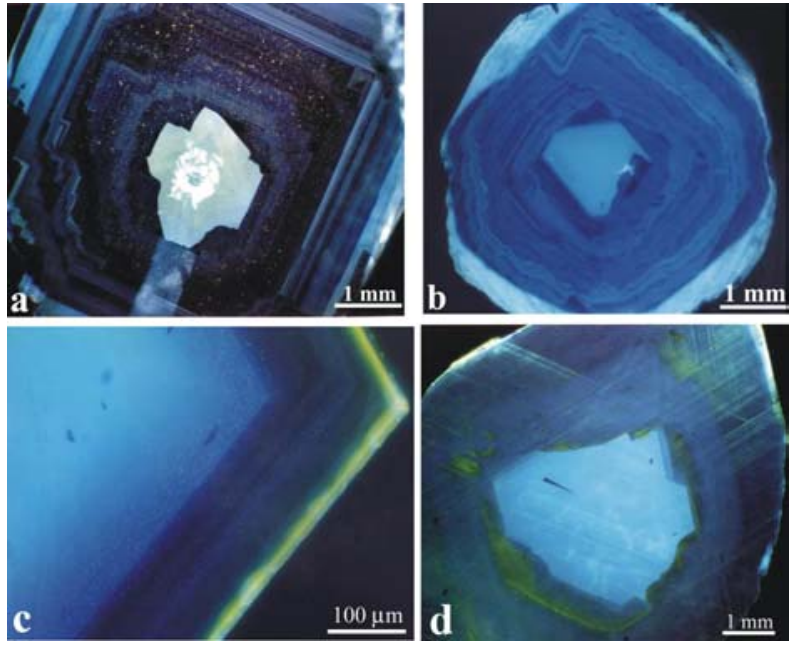

Figure 4: CL images showing features of growth history of diamonds from Snap Lake/King Lake deposit: a, b zoning structure; c - radiation; d-plastic deformation.

the presence of majorite-bearing subcalcic high-Cr high-Mg pyrope inclusions [Pokhilenko et al., 2001a,b] indicating that a definite group of the diamonds crystallized in the roots of a very deep lithospheric mantle at pressures up to $11 \mathrm{Gpa}$., This is quite different from maximum pressures for the lithosphere of normal thickness $(\sim 200 \mathrm{~km}$ and $\mathrm{P} \sim 6-7 \mathrm{GPa})$. The elevated proportion of the diamonds with perfect internal structure (Fig. 2a) can be connected with those diamonds which crystallized at the highest P-T parameters in the deepest levels of the lithosphere underlying the Snap Lake/King Lake area.

The carbon isotope compositions of the Snap Lake diamonds demonstrates that there present at least two distinct groups based on the relationship of the $\mathrm{C}$ isotope value and the $\mathrm{Fe} / \mathrm{Ni}$ ratio in the olivine inclusions [Reutsky et al., 2002].

Our results of the internal structure and morphology study revealed that the Snap Lake/King Lake diamond population have very complex characteristics.

\section{ACKNOWLEDGEMENTS}

Authors are indebted to Winspear Resources Ltd. for providing diamond samples and Diamondex Resources Ltd. for financial support of this study. This work was also supported by Russian Foundation for Basic Research (grants No. 99-05-64686 and 01-05-65166). 


\section{REFERENCES}

Agashev, A.M., Pokhilenko, N.P., McDonald, J.A. et al. 2001. A unique kimberlite-carbonatite primary association in the Snap Lake dyke system, Slave Craton: evidence from geochemical and isotopic studies. Slave-Kaapvaal Workshop. Merrickville, Ontario, Canada, pp. 244-248.

Boyd, S.R., Mattey D.P., Pillinger, C.T., Milledge, H.J., Mendelssohn, M., Seal, M. 1987. Multiple growth events during diamond genesis: an integrated study of carbon and nitrogen isotopes and nitrogen aggregation state in coated stones. Earth Planet. Sci. Lett. 86, 341353.

Pokhilenko, N.P., McDonald, J.A., Hall, A.E. et al. 2001a. Abnormally thick Cambrian lithosphere of the Southeast Slave Craton: evidence from crystalline inclusions in diamonds and pyrope compositions in Snap Lake kimberlites. Slave-Kaapvaal Workshop. Merrickville, Ontario, Canada, pp. 249-252.

Pokhilenko, N.P., Sobolev, N.V., McDonald J.A. et al. 2001b. Crystalline Inclusions in Diamonds from Kimberlites of the Snap Lake Area (Slave Craton, Canada): New Evidences for the Anomalous Lithospheric Structure. Dokl. Akad. Nauk 372 (1), 374-379 (in Russian).

Reutskii, V.N., Pokhilenko, N.P., Hall, A.E., Sobolev, N.V. 2002. Poligeneity of diamonds from kimberlites of Snap Lake (Slave Craton, Canada): results of study of olivine inclusions and carbon isotope composition. Dokl. Akad. Nauk 386 (1), 94-97 (in Russian).

Rylov, G.M., Yefimova, E.S., Sobolev, N.V., Kulipanov, G.N., Kondratyev V.I., Tolochko B.P., Sharafutdinov, M.R. 2001. Study of imperfect natural diamonds with the application of the X-ray synchrotron radiation (the "Laue-SR" method). Nucl. Instr. Methods Phys. Research A, 470, 182-188.

Contact: DA Zedgenizov, Institute of Mineralogy and

Petrography, 3 Koptyuga Ave., 630090, Novosibirsk, Russia, E-mail: zed@uiggm.nsc.ru; NP Pokhilenko, Institute of Mineralogy and Petrography, 3 Koptyuga Ave., 630090,

Novosibirsk, Russia, E-mail: chief@uiggm.nsc.ru 